\title{
EVALUATION OF THE LINEAR MEASUREMENTS BY CONVENTIONAL RADIOGRAPHS AND INDIRECT DIGITAL IMAGES IN THE ENDODONTIC TREATMENT
}

\author{
AVALIAÇÃO DE MEDIDAS LINEARES POR MEIO DE RADIOGRAFIA CONVENCIONAL \\ E DIGITALIZADA NO TRATAMENTO ENDODÔNTICO
}

Nicole KAWAUCHI ${ }^{1}$, Izabel Regina Fischer Rubira BULLEN² ${ }^{2}$ Luiz Eduardo Montenegro CHINELLATO ${ }^{3}$

1- MSc, Graduate Student, School of Dentistry - Bauru, University of São Paulo.
2- PhD, Assistant Professor, School of Dentistry - Bauru, University of São Paulo.
3- PhD, Associate Professor, School of Dentistry - Bauru, University of São Paulo.

Corresponding address: Nicole Kawauchi - Rua Dom Armando Lombardi, 80, apto 14c - Vila Progredior - São Paulo - SP Cep.: 05616-010 - Fone/Fax: (11) 3726-5781

Received: March 24, 2004 - Returned for modification: May 17, 2004 - Accepted: August 23, 2004

\begin{abstract}
I

ntroduction: A successful endodontic therapy depends on the linear measurements obtained by means of radiographs taken during odontometry and also on the application of the established working length up to the final obturation. Objective: The aim of this study was to compare the precision of the linear measurement obtained by means of conventional radiographs and indirect digital images evaluated by the Digora 1.5 software during the different stages of endodontic treatment, as well as to evaluate the tools available on this software. Methods: A total of 160 radiographs of single-rooted teeth were obtained from files, which were analysed and divided in 4 groups comprising odontometry, cone fit, condensation and the final obturation. Analyses of the conventional radiographs and digitized images were performed by five previuosly calibrated examiners. Results: A high level of inter and intra-examiner agreement was observed through application of the Kendall coefficient and the correlation index, respectively. In relation to the results of linear measurement, the two-way variance analyses and the Tukey test revealed that, concerning the method, a statistically significant decrease was observed on the measurement obtained through the digital method when compared to the conventional radiograph $(\mathrm{p}<0,05)$. Moreover, the measurement presented a statistically significant difference among the different stages of endodontic treatment. Regarding interpretation of the digitized image, there was a statistically significant preference towards the Brightness and Contrast tool of the Digora 1.5 software, as evaluated through the Friedman test. Conclusion: The present study demonstrated that image processing by the digital method aids the radiographic interpretation and consequently the determination of reference points for the achievement of the small linear measurements of endodontic treatment. The digital image provided statistically significant smaller linear measurements than those obtained by the conventional method.

Uniterms: Radiography, dental, digital; Endodontics; Endodontics, treatment.
\end{abstract}

\footnotetext{
RESUMO

A

radiologia digital tem sido amplamente difundida na odontologia, especialmente na endodontia. O sucesso do tratamento endodôntico depende das medidas lineares obtidas a partir de radiografias tomadas durante a odontometria, e do seguimento do comprimento de trabalho determinado até a obturação final. Este trabalho objetivou comparar a precisão das medidas lineares obtidas em radiografias convencionais com as imagens digitais indiretas avaliadas pelo programa Digora 1.5, durante as diferentes fases do tratamento endodôntico, bem como avaliar as ferramentas disponíveis neste programa. Foram analisadas 160 radiografias de dentes unirradiculares, dos arquivos da disciplina de Radiologia do departamento de estomatologia, da Faculdade de Odontologia de Bauru - USP, divididos em 4 grupos referentes a odontometria, prova do cone, comprobatória e obturação final. As análises das radiografias convencionais e das imagens digitalizadas foram realizadas por cinco examinadores previamente calibrados. Constatou-se um alto índice de concordância inter e intra-examinadores, respectivamente, por meio do coeficiente de concordância geral de Kendall e pelo índice de correlação. Os resultados relacionados às medidas lineares, submetidos à Análise de Variância a dois critérios e ao teste de Tukey, revelaram: quanto ao método, uma diminuição estatisticamente significante das medidas obtidas pelo método digital em relação à convencional $(\mathrm{p}<0,05)$; e houve diferença estatisticamente significante entre a Fase 1 (odontometria) e a Fase 4 (obturação final) do tratamento endodôntico. Para a interpretação da imagem digitalizada, houve uma preferência estatísticamente significativa pela ferramenta de ajuste de Brilho e Contraste do programa Digora 1.5, analisado pelo teste de Friedman. Os resultados obtidos nesse estudo demonstraram que a imagem digitalizada proporcionou medidas lineares menores do que as realizados pelo método convencional, contudo não está ainda determinado se essa diminuição, corresponderia a uma maior acurácia do sistema, e, portanto, se traria maiores benefícios clínicos.

Unitermos: Radiografia dentária digital; Endodontia; Tratamento do canal radicular.
} 


\section{INTRODUCTION}

Digital radiology has been widely employed in Dentistry, especially in Endodontics. All stages of endodontic treatment, comprising the diagnosis, treatment and followup, require high-quality radiographic images. A successful endodontic treatment depends on the linear measurements achieved on radiographs taken during odontometry, and utilization of the working length established up to final obturation. Thus, it is one of the dental specialties that most requires the improvement of radiographic resources ${ }^{9,23}$.

There are many digital radiology systems commercially available for utilization in Dentistry, for example: RadioVisioGraphy - RVG (Trophy Radiology, Inc.,Marietta, GA), CDR (Schick Technologies Inc., USA), Sens-A-Ray (Regam Medical System AB, Sundsvall, Sweden), Sidexis (Siemens, Benshein, Germany), Visualix/Vixa e Dentoptix (Gendex Dental System, Milan, Italy), Cd Dent (DigiDent DIT, Yoknean, Israel), Dimax 2 (Planmeca Group, Helsinki, Finland) and Digora (Soredex/Orion Corp., Helsinki, Finland) $13,14,20$.The Digora is a digital system based on the image capture by means of an optical plate and has been extensively investigated, mainly because it allows a 50\% reduction in the radiation to the patient and good quality of the radiographic image $e^{2,6,8,13,23}$. Moreover, as regards the radiographic interpretation, image processing may be considered a great advantage of the digital systems, because it allows magnification of the image, 3D visualization, image inversion or brightness and contrast adjustment, besides the tool for linear and angular measurements and histogram levels $5,8,14,22$.

Thus, the aim of this study was to compare the linear measurements achieved on conventional radiographs with the same indirect digital images obtained on the Digora 1.5 software, during the different stages of endodontic treatment. Moreover, the utilization of image processing resources as an auxiliary tool for visualization of structures and improved radiographic interpretation has also been investigated.

\section{MATERIALAND METHODS}

One hundred-sixty periapical radiographs of 40 patients submitted to complete endodontic treatments, assisted at the Post-Graduation clinic of Endodontics of Bauru Dental School, University of Sao Paulo, were selected from the files of the discipline of Radiology, Department of Stomatology, of the same institution. Selection of the sample followed the following criteria: single-rooted teeth and goodquality images.

The study project related to the present outcomes was approved by the Ethics Committee of Bauru Dental School, University of Sao Paulo.

The films for achievement of the conventional radiographs (by bisecting angle technique) were Ektaspeed group E (Kodak, Rochester, NY, USA), which were chemically developed by the time-temperature processing, using chemicals of the same manufacturer and following its recommendations. The exposure time used was 0.4 seconds. The X-ray machine employed was Espectro II (Dabi Atlante, Ribeirao Preto, SP, Brazil), at $10 \mathrm{~mA}$ and $60 \mathrm{Kvp}$.

Evaluation was performed by five examiners, being two radiologists, two endodontists, and a newly graduated general practitioner. All examiners were calibrated for achievement of the measurements, by means of previous evaluation of 10 series of four radiographs using the conventional method and the Digora 1.5 software. The examiners performed two interpretation of each series of radiographs, both in the conventional and digital evaluations, in a time interval of at least ten days between the first and second assessments.

In the first step, the conventional radiographs were ordered according to the stages of treatment: odontometry, cone-fit, lateral condensation and final obturation, and were mounted this way in black cardboard frames for four films and identified by numbers. Evaluation of the conventional radiographs comprised qualitative and quantitative analyses. The first focused on analysis of the radiograph as to the quality of the image to be interpreted. For that purpose, the examiners assigned predetermined scores: poor (radiographs with remarkable distortion, yet allowing visualization of the apex and periapical area of the investigated tooth), acceptable (radiographs with mild distortion, yet allowing good visualization of the apex and periapical area of the investigated tooth), and good (radiograph without any image distortion).

Quantitative analysis comprised measurement of the linear measurements of relevance to endodontic treatment, represented by the distance between the following reference points: tooth apex and file tip for odontometry or stage 1 ; tooth apex and master cone tip for the cone-fit or stage 2; and finally, the tooth apex and end of the filling material for the radiograph to check obturation and final obturation, or stages 3 and 4, respectively.

The distances between the reference points were measured by the five examiners on the conventional radiographs mounted on the frame and positioned on a lightbox, in a dark room. The positioned radiographs were measured with a $3 x$ magnification glass and millimetered ruler to the nearest $0.5 \mathrm{~mm}$. Whenever the measurement was not a multiple of 0.5 , it was recorded as the closest up value. The examiners analyzed ten series of conventional radiographs, and then interpreted the same digitized radiographs on the Digora software after a 30-minute interval. The data achieved were recorded in individual forms for evaluation of the conventional method.

The second step included the same conventional radiographs mounted in a black cardboard frame for four films. The digitization was standardized, being the frame positioned at $5 \mathrm{~cm}$ from the upper limit of the left side of a HP Scanjet 4C scanner (Hewlett Packard), in transparency mode, and transferred to a computer with 8 bits and 300ppi of resolution. The time for scanning was 30 minutes at most for each session of 10 series with four radiographs ${ }^{1,21}$.

The images were saved in TIF format and analyzed on 
the Digora software for Windows, version 1.5 (Soredex, Helsinki - Finland). In an attempt to allow better interpretation on the PC monitor, each frame with 4 digitized radiographs was trimmed on the Adobe Photoshop software version 5.0 (Adobe Systems, Inc., San Jose, California - USA), without any alteration of the image, and once again individually saved in TIF format. A folder was created for each series and was saved in databank.

Analysis of the images comprised qualitative and quantitative assessments.

For the qualitative analysis, the digitized image was evaluated as to the improvement in interpretation with utilization of image processing by means of the software tools, represented by the following options: A, 3D image; B, inverted image; C, brightness and contrast adjustment; $\mathrm{D}$, combination between 3D image and option C; and E, inverted image with brightness and contrast adjustments. When analyzing the digital images, the examiners assigned qualitative scores for each tool employed, which ranged from zero to three, as follows: zero (0), worsened quality of the image; one (1), no alteration (equal); two (2), improvement; or three (3), excellent improvement in the quality of radiographic interpretation of the digitized image compared to the same conventional radiograph. In this moment, the examiner selected the option regarded as having the best quality for interpretation, for accomplishment of the quantitative analysis.

Quantitative analysis of the digitized image comprised repetition of the measurements conducted on the conventional radiographs, yet with utilization of the specific software tool for measurement of distances between two points, employing the same aforementioned reference points. This resource provided measurements in millimeters to the nearest $0.1 \mathrm{~mm}$ (Figure 1). Data were recorded in an individual form, specific for evaluation of the digital image.

The Digora 1.5 software was designed for examination of images achieved by the direct digital method and this way the images would be on a 1:1 ratio. When the image is digitized on a scanner, there may be alterations in this ratio, thus the need to employ a correction factor was verified. This revealed a $0.17 \%$ reduction in the digitized images.

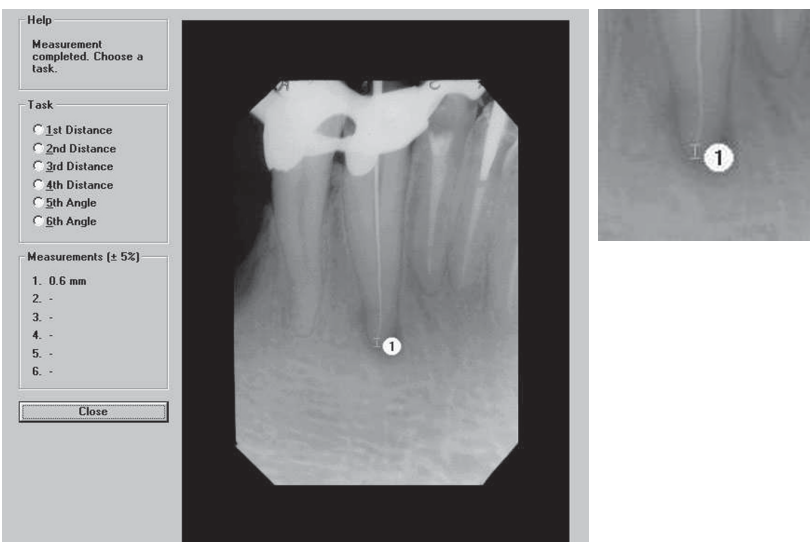

FIGURE 1- Digora Mesuring Tool. (A) Delimiting reference points
Therefore, these values were added to the linear measurements of the evaluation of the digital method. However, there was no significant alteration in the outcomes.

The results achieved were submitted to statistical analysis.

\section{STATISTICAL METHOD}

The intra- and inter-examiner agreements were initially analyzed. Inter-examiner evaluation was conducted by the Kendall's coefficient of concordance, whereas the intraexaminer agreement was assessed by the Dahlberg's test associated to the paired "t" test.

The data related to comparison of the conventional and digital methods were submitted to two-way analysis of variance, both in relation to the method and the stages of endodontic treatment. Moreover, the Tukey test was applied at a significance level of 5\%.

The resources for image processing of the Digora software were evaluated by the Friedman test and by the Student-Newman-Keuls test, at a significance level of $5 \%$.

\section{RESULTS}

The inter-examiner evaluation was conducted by the Kendall's coefficient of concordance ("W"). This coefficient ranges from 0 to 1 , and 1 means perfect concordance (100\%). The present study revealed a variation of 0.76 or $76 \%$ to 0.90 or $90 \%$ of the Kendall's coefficient, indicating a high degree of inter-examiner concordance. Moreover, there were no significant differences in the "W" coefficients between the values found by the conventional and digital methods (Table 1).

Intra-examiner agreement was evaluated by the Dahlberg's test and correlation index " $r$ ". This index follows the same parameter as the Kendall's coefficient of concordance, ranging from 0 to 1 , being 1 the maximum value. High intra-examiner indexes were found, similarly to the interexaminer concordance. Table 2 reveals that the digital method displayed slightly higher values, reaching a highest index of 0.99 , i.e. almost perfect (examiner 5 , stage 1 ). On the other hand, despite of the slightly lower indexes observed for the conventional method, the lowest index was 0.68 (examiner 2 , stage 2), therefore indicating high intra-examiner

TABLE 1- Kendall's coefficient of concordance ("W") for inter-examiner evaluation

\begin{tabular}{lcc}
\hline STAGES & “W”- Conventional & “W"- Digital \\
\hline F1 & 0.90 & 0.89 \\
F2 & 0.85 & 0.86 \\
F3 & 0.80 & 0.84 \\
F4 & 0.79 & 0.76 \\
\hline
\end{tabular}


agreement.

The results obtained by the inter- and intra-examiner evaluations demonstrated the reliability of the linear measurements accomplished by the five examiners.

The two-way analysis of variance was utilized to check the occurrence of these facts to each variable (method employed and stage of endodontic treatment). The results indicated statistically significant differences between the measurements obtained on the digital and conventional methods, as well as between the stages of treatment, at the level of $\mathrm{p}<0.05$. However, no correlation was found between the variables method and endodontic stage (Table 3).

The Tukey HSD test was applied at a significance level of $\mathrm{p}<0.05$ for the same groups. This test revealed a statistically significant difference between the digital and conventional methods (Table 4). The Tukey HSD test also provided the general means, and the mean of the conventional method ( $\mathrm{M}=1.42 \mathrm{~mm}$ ) was higher than that of the digital method $(\mathrm{M}=1.22)$. Similarly, the Tukey test (HSD) was applied for analysis of the differences between the stages of endodontic treatment, being F1 odontometry; F2 cone-fit ; F3 check obturation, and F4 final obturation. The results demonstrated statistical difference $(p<0.05)$ in the measurements between stage 1 , with a significance level of 0.033 and mean of $1.58 \mathrm{~mm}$, and stage 4 , with a mean of 1.14 mm (Table 5).

The means of the linear measurements for each stage displayed a reduction throughout treatment, being the highest mean observed for stage $1(\mathrm{M}=1.58 \mathrm{~mm})$, followed by the cone-fit radiograph $(\mathrm{M}=1.32 \mathrm{~mm})$, the radiograph to check obturation $(\mathrm{M}=1.24 \mathrm{~mm})$ and the final obturation, with the lowest mean of $1.14 \mathrm{~mm}$. Therefore, there was a $0.44-\mathrm{mm}$ decrease between F1 and F4, which was statistically significant. Figure 2 demonstrates the lower values obtained on the digitized image in stages 1, 2, 3 and 4, with the smallest difference for stage 4.

The results achieved by the Friedman's test for repeated measurements, for evaluation of the tools for image processing of the Digora software, demonstrates a significant improvement $(\mathrm{p}<0.001)$ with utilization of the digital system for radiographic interpretation. Thus, verification of the difference between groups was conducted by the StudentNewman-Keuls multiple comparisons test, the result of which revealed a statistically significant difference between the tools for image processing of Digora $(\mathrm{p}<0.05)$. According to the outcomes of this statistical test, associated to analysis of the general mean, a ranking of the preference for the tools by the five examiners could be established, being the Brightness and Contrast adjustment the first preferred tool, and the 3D image the last (Figure 3).

\section{DISCUSSION}

The endodontic treatment requires a remarkable number of radiographs for its proper accomplishment, thus invariably

TABLE 2- Intra-examiner evaluation at two different times $\left(T_{1}\right.$ e $\left.T_{2}\right)$ by application of the Dahlberg's test and correlation between them ("r")

\begin{tabular}{ccccccccc}
\hline EXAMINER & \multicolumn{1}{c}{ “r” } & & & \\
& F1/C & F2/C & F3/C & F4/C & F1/D & F2/D & F3/D & F4/D \\
\hline 1 & 0.97 & 0.93 & 0.84 & 0.92 & 0.96 & 0.92 & 0.80 & 0.92 \\
2 & 0.89 & 0.68 & 0.93 & 0.76 & 0.95 & 0.93 & 0.93 & 0.94 \\
3 & 0.98 & 0.97 & 0.95 & 0.90 & 0.95 & 0.94 & 0.94 & 0.97 \\
4 & 0.88 & 0.79 & 0.89 & 0.79 & 0.92 & 0.74 & 0.93 & 0.90 \\
5 & 0.97 & 0.97 & 0.91 & 0.92 & 0.99 & 0.98 & 0.97 & 0.78 \\
\hline
\end{tabular}

TABLE 3- Two-way analysis of variance for comparison between the conventional (C) and digital (D) methods, between the stages of endodontic treatment (F1, F2, F3 and F4) and interaction between variables

\begin{tabular}{lllllll}
\hline & $\begin{array}{l}\text { Degrees of } \\
\text { freedom } \\
\text { (effects) }\end{array}$ & $\begin{array}{l}\text { Mean squares } \\
\text { (effects) }\end{array}$ & $\begin{array}{l}\text { Degrees of } \\
\text { freedom } \\
\text { (error) }\end{array}$ & $\begin{array}{l}\text { Mean squares } \\
\text { (error) }\end{array}$ & F & p \\
\hline METHOD & $1^{*}$ & $3.004094^{*}$ & $39^{*}$ & $0.072909^{*}$ & $41.20348^{*}$ & $0.000000^{*}$ \\
STAGES & $3^{*}$ & $2.850726^{*}$ & $117^{*}$ & $1.014704^{*}$ & $2.80942^{*}$ & $0.042569^{*}$ \\
INTERACTION & 3 & 0.045476 & 117 & 0.064674 & 0.70315 & 0.552001 \\
\hline
\end{tabular}

* significant 
exposing the patient to higher X-ray doses. Thus, the clinical applicability of digital systems in Endodontics has been investigated with a view to reduce the radiation dose to the patient, optimize the treatment and improve the image quality for radiographic interpretation ${ }^{2}$. The present study investigated whether there was any alteration in the linear measurements achieved by the conventional and digital radiographic methods during endodontic treatment. Besides, it has analised the resources of image processing of the Digora software to increase the accuracy and precision in the achievement of linear measurements.

Evaluation of the inter- and intra-examiner agreement is highly important in studies related to radiographic interpretation, because it establishes the reliability of the results achieved ${ }^{10}$. The reliability of radiographic interpretation may be affected by several factors, such as professional formation, examiner's experience, quality of the radiograph and conditions of the environment for interpretation ${ }^{5,10}$. The inter-examiner agreement was assessed by the Kendall's coefficient of concordance and the intra-examiner agreement was evaluated by the Dahlberg's test associated to the paired " $t$ " test. Both revealed high indexes of concordance, which indicate a proper control of the above mentioned factors. As regard the examiners, even though having different specialties, they received a proper calibration in relation to establishment of reference points manipulation of the digital and conventional equipments to set the measurement. However, some differences were observed on the examiners' performance related to their experience. No influence from the environmental conditions for radiographic interpretation was found in the present study, since all examiners

TABLE 4 - TUKEY test (HSD) for establishment of the group (C / D) with significant difference as to the method

\begin{tabular}{lll}
\hline & $\begin{array}{l}\text { CONVENTIONAL } \\
M=1,420781\end{array}$ & $\begin{array}{l}\text { DIGITAL } \\
M=1,227000\end{array}$ \\
\hline $\begin{array}{ll}\text { CONVENTIONAL } \\
\text { DIGITAL }\end{array}$ & $0.000117^{*}$ & $0.000117^{*}$ \\
\hline
\end{tabular}

*significant $\quad M=$ Mean conducted the evaluations under the same conditions.

The results revealed high indexes of inter- and intraexaminer agreement, regardless of the interpretation method employed, thus indicating the feasiblity of utilization of the digital system for the achievement of linear measurements with the same reproducibility as the conventional method.

As regards the stages of endodontic treatment, there was a statistically significant difference between

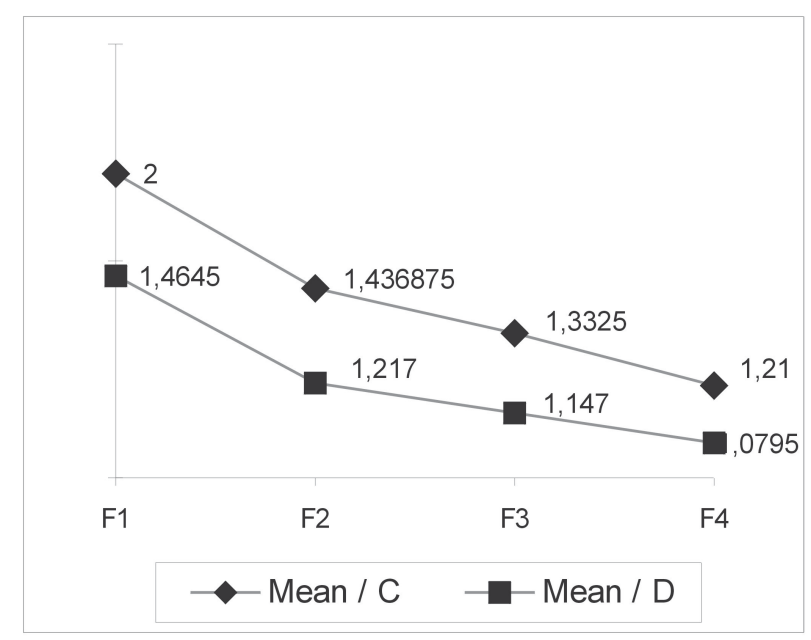

FIGURE 2- TUKEY test (HSD) for determination of the general means and pattern of difference between the groups, methods and stages

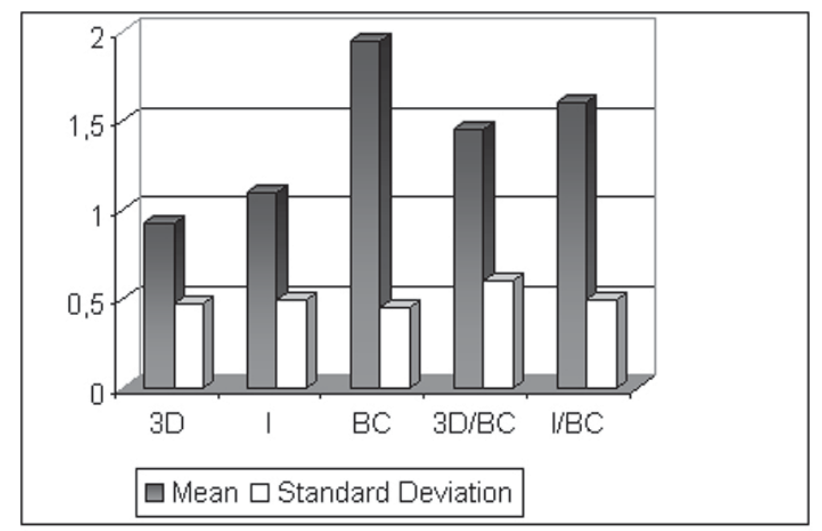

FIGURE 3- General mean and standard deviation of the tools for image processing

TABLE 5- TUKEY test (HSD) for establishment of the group (F1, F2, F3 and F4), as to the stages of endodontic treatment

\begin{tabular}{|c|c|c|c|c|}
\hline STAGES & $\begin{array}{c}F 1 \\
M=1.584125\end{array}$ & $\begin{array}{c}F 2 \\
M=1.326938\end{array}$ & $\begin{array}{c}F 3 \\
M=1.239750\end{array}$ & $\begin{array}{c}F 4 \\
M=1.144750\end{array}$ \\
\hline $\mathrm{F} 1$ & & 0.374426 & 0.140105 & $0.033699 *$ \\
\hline $\mathrm{F} 2$ & 0.374426 & & 0.947151 & 0.663272 \\
\hline F3 & 0.140105 & 0.947151 & & 0.933038 \\
\hline $\mathrm{F} 4$ & $0.033699^{*}$ & 0.663272 & 0.933038 & \\
\hline
\end{tabular}

$\mathrm{p}<0.05 \quad \mathrm{M}=$ Mean


odontometry and final obturation, both for the digital and conventional methods. There was a gradual decrease in the measurements during treatment, secondary to the technique employed and achieving the final therapeutic goal. However, odontometry revealed statistically significantly higher values compared to the final obturation, since it was taken before instrumentation, consequently with smaller files, which are more difficult to observe. Thus, some authors suggest that this difference might be reduced by the achievement of a radiograph with the larger file employed after completion of instrumentation ${ }^{3,23}$. In the present study, the difference between the initial and final measurements was $0.45 \mathrm{~mm}$ for the conventional method and $0.37 \mathrm{~mm}$ for the digital method. Despite its statistical significance, this difference is not clinically relevant, since it was smaller than $0.5 \mathrm{~mm}^{11}$. A relevant aspect of this evaluation was the fact that measurements taken during odontometry presented higher inter-examiner agreement in both methods applied, and the indexes were gradually reduced according to the treatment stage. On the other hand, the small measurements found in final obturation provided less visual acuity, being influenced by other factors related to the ability of interpretation of each individual, thus reducing the interexaminer concordance.

Finally, as regards the linear measurements, the digital method with utilization of the Digora 1.5 software displayed statistically significantly smaller values compared to the conventional method when submitted to the two-way analysis of variance and the Tukey HSD test. A mean reduction of $0.193 \mathrm{~mm}$ was found for the measurements obtained by the Digora, probably because the digital system provides a $0.1-\mathrm{mm}$ precision for linear distances. However, this reduction observed in the measurements obtained by the digital method was not clinically relevant.

Considering these outcomes, it was observed that the conventional and digital methods displayed quite similar values and therefore are indicated for establishment of the working length in Endodontics, in agreement with other authors ${ }^{16,17,18,19}$. However, these same authors agreed that the tools for image processing improve the quality of interpretation, enhancing the achievement of measurements by magnification or zoom, altering the brightness and contrast, inverting the image (negative) or converting it in a 3D image.

In the present study, the outcomes submitted to the Friedman's test for repeated measurements revealed high significance $(\mathrm{p}<0.001)$ for all options of image processing employed. Differentiation of the performance of each option was performed by application of the Student-NewmanKeuls multiple comparisons test, which established a ranking between the tool options. The tools presenting the worst performance were the $3 \mathrm{D}$ image, followed by the inverted image. In some studies, the 3D image has aided the establishment of distances, yet most did not reveal any improvement ${ }^{23}$. The inverted image aims, converting the clear shades in dark shades and vice-versa, creating a negative image of the digitized image. This effect has been recommended by some authors for establishment of the working length ${ }^{7,11}$ yet it seems to be more useful for detection of periapical lesions and root resorptions ${ }^{4,19}$.

In fact, these image resources, associated to the brightness and contrast adjustment, yielded a significant improvement in the image. Brightness and contrast usually are the most frequently employed tools for manipulation of the digital image. This resource provided a significant improvement in the analysis of the digitized radiograph. Other authors agreed with these outcomes 12, 13, 15, 20, 22, emphasizing that simpler resources such as brightness and contrast were the most effective ${ }^{14,24}$.

\section{CONCLUSION}

The present study demonstrated that image processing by the digital method aids the radiographic interpretation and consequently the determination of reference points for the achievement of the small linear measurements of endodontic treatment. The digital image provided statistically significant smaller linear measurements than those obtained by the conventional method. However, it remains to be determined whether this decrease would correspond to higher accuracy of the system and thus provide clinical benefits.

\section{ACKNOWLEDGMENT}

We thanks CAPES - Coordenação de Aperfeiçoamento de Pessoal de Nível Superior for financial support.

\section{REFERENCES}

1- Attaelmanan A, Borg E, Grondahl HG. Digitisation and Display of intra-oral films. Dentomaxillofac Radiol 2000 Mar; 29(2):97-102.

2- Berkhout WE, Sanderink GC, Van Der Stelt PF. Does digital radiography increase the number of intraoral radiographs? A questionnaire study of Dutch dental practices. Dentomaxillofac Radiol 2003 Mar;32(2):124-7.

3- Brandão EG Avaliação do comprimento de condutos radiculares utilizando um sistema de radiografia digitalizada. Porto Alegre; 2000. [Dissertação de Mestrado - Faculdade de Odontologia, Pontifícia Universidade Católica do Rio Grande do Sul.]

4- Brocklebank LM. Dental radiology: capture your image. Dent Update 1998 Apr; 25(3):94-102.

5- Capelozza ALA Estudo comparativo de algumas lesões do periápice através da imagem radiográfica convencional e imagem digital indireta utilizando o programa Adobe Photoshop 5.0. Bauru; 2001. [Tese de Livre-Docência - Faculdade de Odontologia de Bauru, Universidade de São Paulo].

6- Eikenberg S, Vandre R. Comparison of digital dental x-ray system with self-developing film and manual processing for endodontic file length determination. J Endod 2000 Feb; 26(2):65-7. 
7- Ellingsen MA, Hollender LG, Harrington GW. Radiovisiography versus conventional radiography for detection of small instruments in endodontic length determination. Part I. In vitro evaluation. J Endod 1995 Jun; 21(6): 326-31.

8- Farman AG. Fundamentals of image acquisition and processing in the digital era. Orthod Craniofac Res 2003;6 (Suppl 1):17-22.

9- Garcia AA, Navarro LF, Castelló VU, Laliga LM. Evaluation of digital radiography to estimate working length. J. Endod. 1997 Jun; 23(6):363-5.

10- Goldman M, Pearson AH, Darzenta N Reability of radiographic interpretations. Oral Surg 1974 Aug; 38(2):287-93.

11- Griffiths BM Comparison of three imaging techniques for assessing endodontic working length. Int Endod J 1992 Nov; 25(6): 279-87.

12- Hildebolt CF Quantitative evaluation of digital dental radiograph imaging systems. Oral Surg 1990 Nov; 70 (5):661-8.

13- Hildebolt CF, Couture RA, Whiting BR Dental photostimulable phosphor radiography. Dent Clin N Amer 2000 Apr.; 44(2):273-97.

14- Khademi JA Digital images \& sound. J dent Educ 1996 Jan; 60(1):41-6.

15- Kullendorff B, Nilsson M. Diagnostic accuracy of direct digital dental radiography for detection of periapical bone lesions. II. Effects on diagnostic accuracy after application of image processing. Oral Surg 1996 Nov; 82 (5):585-9.

16- Loushine ERJ Measurement of endodontic file lengths: calibrated versus uncalibrated digital images. J Endod 2001 Dec; 27(12):77981

17- Lozano A, Forner L, Llena C. In vitro comparison of root-canal measurement with conventional and digital radiology. Int Endod J 2002 Jun; 35(6):542-50.

18- Melius B, Jiang J, Zhu Q. Measurement of the distance between the minor foramen and the anatomic apex by digital and conventional radiography. J Endod 2002 Feb; 28(2):125-6.

19- Mentes A, Gencoglu N. Canal length evaluation of curved canals by direct digital or conventional radiography. Oral Surg 2002 Jan; 93(1):88-91.

20- Naoum HJ, Chandler NP, Love RM Conventional versus storage phosphor-plate digital images to visualize the root canal system contrasted with a radiopaque medium. J Endod 2003 may; 29(5):34952.

21- Ohki M, Okano T, Nakamura T. Factors determining the diagnostic accuracy of digitized conventional intraoral radiographs. Dentomaxillofac Radiol 1994 May; 23(2):77-82.

22- Preston JD Digital radiography-not if, but when. J Calif dent Ass 1999 Dec.; 27 (12):935-41.

23- Vale IS. Visibilidade de algumas limas endodônticas por meio do sistema de imagem digital Digora e de três filmes radiográficos periapicais. Bauru, 2001. 226p. Tese (Doutorado) - Faculdade de Odontologia de Bauru, Universidade de São Paulo.

24- Wenzel A Accuracy of caries diagnosis in digital images from charge-coupled device and storage phosphor system: an in vitro study. Dentomaxillofac Radiol 1993 Aug.; 22 (3):131-4. 